\title{
A wild Cucurbita genome reveals the role of structural variants and introgression in domestication
}

Josué Barrera-Redondo ${ }^{1,6, *}$, Guillermo Sánchez-de la Vega ${ }^{1,6}$, Jonás A. AguirreLiguori $^{2}$, Gabriela Castellanos-Morales ${ }^{3}$, Yocelyn T. Gutiérrez-Guerrero ${ }^{1}$, Xitlali Aguirre-Dugua1, Erika Aguirre-Planter ${ }^{1}$, Maud I. Tenaillon ${ }^{4}$, Rafael Lira-Saade ${ }^{5, *}$, Luis E. Eguiarte ${ }^{1, *}$

${ }^{1}$ Departamento de Ecología Evolutiva, Instituto de Ecología, Universidad Nacional Autónoma de México, Circuito Exterior s/n Anexo al Jardín Botánico, 04510 Ciudad de México, México.

${ }^{2}$ Department of Ecology and Evolutionary Biology, University of California, Irvine, CA.

${ }^{3}$ Departamento de Conservación de la Biodiversidad, El Colegio de la Frontera Sur, Villahermosa, Carretera Villahermosa-Reforma km 15.5 Ranchería El Guineo 2ª sección, 86280 Villahermosa, Tabasco, México.

${ }^{4}$ Génétique Quantitative et Evolution - Le Moulon, Université Paris-Saclay, Institut National de Recherche pour l'Agriculture, l'Alimentation et l'Environnement, Centre National de la Recherche Scientifique, AgroParisTech, Gif-sur-Yvette, France.

${ }^{5}$ UBIPRO, Facultad de Estudios Superiores Iztacala, Universidad Nacional Autónoma de México, Av. de los Barrios \#1, Col. Los Reyes Iztacala, Tlalnepantla, Edo. de Mex 54090, México.

${ }^{6}$ These authors contributed equally to this article.

*Correspondence: Josué Barrera-Redondo (josue barrera@comunidad.unam.mx), Rafael Lira-Saade (rlira@unam.mx), Luis E. Eguiarte (fruns@unam.mx) 


\section{Abstract}

Despite their economic importance and well-characterized domestication syndrome, the genomic impact of domestication and the identification of variants underlying the domestication traits in Cucurbita species (pumpkins and squashes) is currently lacking. Cucurbita argyrosperma, also known as cushaw pumpkin or silver-seed gourd, is a Mexican crop consumed primarily for its seeds rather than fruit flesh. This makes it a good model to study Cucurbita domestication, as seeds were an essential component of early Mesoamerican diet and likely the first targets of human-guided selection in pumpkins and squashes. We obtained populationlevel data using tunable Genotype by Sequencing libraries for 192 individuals of the wild and domesticated subspecies of $C$. argyrosperma across Mexico. We also assembled the first wild Cucurbita genome at a chromosome level. Comparative genomic analyses revealed several structural variants and presence/absence of genes related to domestication. Our results indicate a monophyletic origin of this domesticated crop in the lowlands of Jalisco. We uncovered candidate domestication genes that are involved in the synthesis and regulation of growth hormones, plant defense mechanisms, flowering time and seed development. The presence of shared selected alleles with the closely related species Cucurbita moschata suggests domestication-related introgression between both taxa.

\section{Keywords}

Squash, domestication, Mesoamerica, structural variants, selective scans. 


\section{Introduction}

Domestication is an evolutionary process where human societies select, modify and eventually assume control over the reproduction of useful organisms. A mutualistic relationship emerges from this interaction, where humans exploit a particular resource of interest, while the domesticated organism benefits from increased fitness and extended geographical range (Meyer and Purugganan, 2013; Zeder, 2015). This is well illustrated in Cucurbita L. (pumpkins, squashes and some gourds), where human-guided domestication and breeding have considerably extended their distribution despite the extinction of their natural dispersers (e.g., mastodons and similar megafauna) (Kistler et al., 2015). Today, Cucurbita stand as successful crops grown and consumed worldwide, with a global annual production of $\sim 24$ million tons (Paris, 2016).

With ca. 21 taxa, the Cucurbita genus has experienced independent domestication events in five species (Castellanos-Morales et al., 2018; Sanjur et al., 2002). Each Cucurbita crop experienced unique selection for specific traits, predominantly defined by the nutritional and cultural needs of early human populations in America (Zizumbo-Villarreal et al., 2012). However, many domestication traits are common to domesticated Cucurbita, including the loss of bitter compounds (cucurbitacins), the loss of physical defense mechanisms (e.g., urticating trichomes), the loss of seed dormancy, the enlargement of fruits and seeds, and the diversification of fruit morphology (Chomicki et al., 2019; Paris, 2016).

The initial steps of Cucurbita domestication were most likely directed towards seed rather than flesh consumption (Whitaker and Cutler, 1965). Seeds are rich in both carbohydrates and fatty acids, and cucurbitacins can be removed through boiling and washing; processes that are still employed for the consumption of wild Cucurbita seeds in Western Mexico (Zizumbo-Villarreal et al., 2012). Because the cultivation of $C$. argyrosperma (pipiana squash, cushaw pumpkin or silver-seed gourd) is directed towards seed production rather than fruit flesh, it stands as an excellent model to investigate the early steps of Cucurbita domestication. 
Cucurbita argyrosperma subsp. argyrosperma (argyrosperma hereafter) was domesticated in Mesoamerica from its wild relative Cucurbita argyrosperma subsp. sororia (sororia hereafter), according to archaeological and genetic evidence (Sanjur et al., 2002; Piperno et al., 2009; Sánchez-de la Vega et al., 2018). Argyrosperma exhibits morphological differences from sororia, including larger fruits, larger seeds and lack of urticating trichomes (Fig. 1). The earliest archaeological record of argyrosperma is presumed to be from 8,700-year-old phytoliths in the Central Balsas Valley (Guerrero), although its taxonomic identity remains uncertain (Piperno et al., 2009). Its earliest unambiguous archaeological remain is a 5,035-year-old peduncle from the Ocampo caves in Tamaulipas (Smith, 1997). C. argyrosperma is a monoicous outcrossing species and gene flow has been previously described between the domesticated and wild subspecies (Montes-Hernandez and Eguiarte, 2002). Both subspecies are sympatrically distributed throughout the Pacific Coast of Mexico and Central America, with a few populations scattered in the coast of the Gulf of Mexico (Lira et al., 2016; Sánchez-de la Vega et al., 2018). The domesticated taxon is also distributed in the Yucatan Peninsula, where its wild counterpart is absent (Sánchez-de la Vega et al., 2018).

Studies that address the genetic basis of Cucurbita domestication are a necessary step towards a deeper understanding of the history of these economically important crops, as well as the development of new breeding strategies and the effective conservation of its genomic resources (Lira et al., 2016; Chomicki et al., 2019). To contribute in this direction, we report here the first genome assembly of the wild relative sororia, which complements the existing assembly of argyrosperma (Barrera-Redondo et al., 2019). The comparison between the genomes allowed us to find genomic structural variants between both subspecies. We characterized a large sample of argyrosperma landraces (117 individuals from 19 locations) and sororia accessions (50 individuals from 4 locations) using genome-wide data to investigate their demographic history and propose a domestication scenario. We also performed selection scans throughout the 
genome of $C$. argyrosperma to detect candidate regions associated with the domestication of this species.

\section{Results}

\section{Genome assembly of $C$. argyrosperma subsp. sororia}

We sequenced the genome of a wild individual of subspecies sororia using Illumina HiSeq4000 (213x coverage) and PacBio Sequel (75.4x coverage). The genome was assembled in 828 contigs with an N50 contig size of $1.3 \mathrm{Mbp}$ and an L50 of 58 contigs (Table S1). A BUSCO analysis (Simão et al., 2015) against the embryophyta odb9 database detected $92.8 \%$ of complete BUSCOs, $1.2 \%$ fragmented BUSCOs and $6.0 \%$ missing BUSCOs within the genome assembly, similarly to other Cucurbita genome assemblies (Barrera-Redondo et al., 2019; Sun et al., 2017). We predicted 30,694 protein-coding genes within the genome assembly using BRAKER2 (Hoff et al., 2016). Around $35.8 \%$ of our sororia genome assembly is composed of transposable elements (TEs), slightly higher than the $34.1 \%$ of TEs found in a previous argyrosperma assembly (Barrera-Redondo et al., 2019).

The genome assembly of argyrosperma was previously assembled in 920 scaffolds (Barrera-Redondo et al., 2019), so we aimed to reach chromosome-level assemblies for both the sororia and the argyrosperma genomes. We anchored $99.97 \%$ of the argyrosperma genome assembly and $98.8 \%$ of the sororia genome assembly into 20 pseudomolecules using RaGOO (Alonge et al., 2019), which corresponds to the haploid chromosome number in Cucurbita (Whitaker and Bemis, 1975). Both assemblies show high synteny conservation across the genus (Fig. S1) and confirm a previously reported inversion in chromosome four that is shared with C. moschata (Sun et al., 2017). 


\section{Structural variants between the wild and domesticated genomes}

We compared the genome of argyrosperma against the genome of sororia (Fig. 2). Some of the centromeres in the genome of sororia were larger than in argyrosperma, possibly due to a better assembly of the repetitive regions. We found several structural variants (SVs) such as copy-number variants (CNVs), inversions, translocations and unalignable regions between the wild and the domesticated genomes (Table S2). The size of the sororia genome assembly is $\sim 254 \mathrm{Mbp}, 9.23 \%$ larger than the genome assembly of argyrosperma (BarreraRedondo et al., 2019), which could be partially explained by these SVs. The genes found within the CNV losses in argyrosperma were enriched in pectinesterases and microtubule-based processes (Table S2). We also found sucrose-6 $F_{-}$ phosphate phosphohydrolase (SPP) within a CNV loss in argyrosperma. The genomes of argyrosperma and sororia share some common genes within their unalignable regions, such as microtubule-associated proteins and genes related to tryptophan biosynthesis (Table S2), suggesting that those regions contain highly divergent sequences and are not limited to presence/absence variants. However, other unaligned regions contain more genes in sororia than in argyrosperma, including some proteolytic enzymes and sucrose biosynthetic genes that are absent in the argyrosperma genome (Table S2), suggesting that presence/absence variants are also included within the unalignable regions.

\section{Population data and SNP genotyping}

We used samples previously collected throughout Mexico (Sánchez-de la Vega et al., 2018) corresponding to 117 individuals of argyrosperma, 50 individuals of sororia, 19 feral individuals of argyrosperma previously reported to have a semiwild phenotype and a cultivated genotype based on microsatellite data (Sánchezde la Vega et al., 2018) and 6 individuals of $C$. moschata (the domesticated sister species of C. argyrosperma), that were used as outgroups (Table S3). The samples were sequenced using the tunable Genotype by Sequencing (tGBS) method (Ott et al., 2017) to obtain genome-wide genetic information of the $C$. 
argyrosperma populations. The reads were quality-filtered and mapped against the chromosome-level genome assemblies of argyrosperma and sororia to predict single nucleotide polymorphisms (SNPs) and assess possible reference biases in the SNP prediction. Using the reference genome of argyrosperma, we obtained an initial dataset consisting of 12,813 biallelic SNPs with a mean read depth of 50 reads per SNP and a minor allele frequency (MAF) of at least 1\% (13k dataset, Dataset S1). We also mapped the whole-genome Illumina reads of argyrosperma and sororia, as well as the whole-genome sequencing of a $C$. moschata individual and a $C$. okeechobeensis subsp. martinezii individual (a closely related wild Cucurbita species), against the reference genome of argyrosperma to obtain a dataset of $11,498,421$ oriented biallelic variants (SNPs and indels) across the genome that was used to assess introgression and incomplete lineage sorting (Dataset S2).

\section{Demographic history of $\boldsymbol{C}$. argyrosperma during its domestication}

We eliminated the SNPs that deviated from Hardy-Weinberg equilibrium (exact test with $p<0.01$ ) and pruned nearby SNPs under linkage disequilibrium (LD with an $r^{2}>0.25$ in $100 \mathrm{kbp}$ sliding windows) from the $13 \mathrm{k}$ dataset to retrieve a set of 2,861 independent SNPs that could be used for demographic analyses.

We found similar genetic variation in sororia and argyrosperma, regardless of the reference genome used (average nucleotide diversity $\pi$ range 0.095 - 0.098 for both taxa, see Table S4). At a population scale, the wild population in Jalisco had the highest genetic diversity within sororia, while the highest diversity in argyrosperma was found in the Pacific Coast of Mexico (Table S5). The domesticated and wild populations of $C$. argyrosperma displayed low genetic differentiation ( $F_{S T}=0.0646 ; 95 \%$ confidence interval from 0.0565 to 0.0751 ), while feral populations were more closely related to argyrosperma $\left(F_{\mathrm{ST}}=0.0479\right)$ than with sororia $\left(F_{\mathrm{ST}}=0.1006\right)$. 
We used SNPhylo (Lee et al., 2014) and ADMIXTURE (Alexander et al., 2009) to evaluate the genealogical relationships and genetic structure among the wild and domesticated populations of $C$. argyrosperma. We confirmed the genetic differentiation between sororia and argyrosperma, as detected by the FST analyses. Our Maximum Likelihood (ML) tree groups all the argyrosperma populations in a single monophyletic clade (Fig. 3A). We found additional genetic differentiation between the sororia populations in Southern Mexico (populations 13 ) and the sororia populations in Jalisco (population 4), in both the ADMIXTURE assignations (Fig. 3B) and their positions in the ML tree (Fig. 3A). The sororia populations of Jalisco are genetically closer to argyrosperma, as shown by their paraphyletic position in the ML tree (Fig. 3A). Consistent with a domestication in the lowlands of Western Mexico, the argyrosperma populations of Guerrero and Jalisco represent the basal branches of the argyrosperma clade (Fig. 3A), all showing instances of genetic similarity to the sororia populations in Jalisco in the four genetic groups (K) of ADMIXTURE (Fig. 3B). The argyrosperma populations in Western Mexico (populations 5-17) are genetically differentiated from the Eastern populations (populations 18-26), with a possible recent anthropogenic dispersion event of Eastern populations into Onavas, Sonora (population 19; Fig. 3B-C). These four genetic groups are also retrieved in a principal component analysis (PCA; Fig. S2). The ADMIXTURE results (Fig. 3B) uncovered admixture events between some sororia and argyrosperma populations. This pattern is evident in the populations of Oaxaca and Sinaloa (populations 14 and 18; Fig. 3C). The feral populations are consistently grouped alongside their sympatric domesticated populations within argyrosperma (Fig. 3A-B), indicating that these populations diverged recently from nearby domesticated populations.

We used Fastsimcoal 2 (Excoffier and Foll, 2011) to test whether argyrosperma was domesticated from a sororia population in Southern Mexico or from a sororia population in Jalisco. Given that gene flow has been previously observed between argyrosperma and sororia (Montes-Hernandez and Eguiarte, 2002), we compared three different gene flow models (continuous gene flow, secondary contact or no 
gene flow) for each scenario (Fig. 4A). A comparison between models using the Akaike Information Criterion indicates that the Jalisco domestication model with secondary contact (i.e., extant gene flow after initial genetic isolation between subspecies) is the most likely of the domestication scenarios assayed.

\section{Domestication sweeps in C. argyrosperma}

In order to perform the tests to detect selective sweeps associated with the domestication of $C$. argyrosperma, we removed from the $13 \mathrm{k}$ dataset the $C$. moschata individuals as well as the feral individuals of $C$. argyrosperma. We used the $1 \%$ MAF threshold for this subset, obtaining a 10,617 SNP dataset suitable to detect selective sweeps, with a marker density of 44 SNPs per Mb. LD was limited within the dataset, with a mean pairwise $\mathrm{r}^{2}$ of 0.1 (Fig. S3). We performed two FSTbased tests as implemented in BayeScEnv (de Villemereuil and Gaggiotti, 2015) and PCAdapt (Luu et al., 2017) to detect selective sweeps between the domesticated and the wild populations of $C$. argyrosperma (Fig. 5A). BayeScEnv

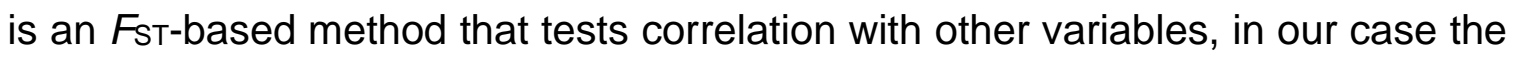
wild or domesticated nature of each population (coded as 0 and 1, respectively). PCAdapt does not require an a priori grouping of individuals into wild/domesticated, as we used the two principal components of a PCA to control for the underlying genetic structure between subspecies (Fig. S2).

We discovered 338 outlier SNPs with either BayeScEnv (91 outliers, Fig. 5A) or PCAdapt (266 outliers, Fig. 5B). We used C. moschata and C. okeechobeensis subsp. martinezii as outgroups to determine the direction of the putative selective pressures for each SNP outlier, as well as determining possible introgression or incomplete lineage sorting between sororia, argyrosperma and C. moschata. We found that 81 of the outliers corresponded to selective signals in argyrosperma, while 215 outliers corresponded to selective signals in sororia (Fig. 5). We could not determine the direction of selection for 22 SNP outliers, and 20 outliers showed signals of introgression or incomplete lineage sorting. Only 19 SNPs were shared 
as outliers by both tests, from which 15 corresponded to selective signals in sororia and 4 showed putative signals of introgression.

We identified several instances of either genetic introgression or incomplete lineage sorting between $C$. moschata and both argyrosperma (ABBA sites) or sororia (BABA sites) (Fig. S4). We performed a genome-wide D-statistic analysis and found significantly more instances of shared derived variants between argyrosperma and $C$. moschata than between sororia and $C$. moschata (blockjackknife $p$-value $=0.0014)$, obtaining an overall admixture fraction $f_{G}$ of 0.01 (Table S6). From the 20 outliers with putative signals of introgression, 12 correspond to ABBA sites and 8 correspond to BABA sites (Fig. 5).

We found 125 protein-coding genes and 7 long-noncoding RNAs including outlier SNPs within their structure (i.e., introns, exons, UTRs), which were assigned according to the observed direction of the putative selective signals (Table S7). Among the genes under putative selection in sororia were a homolog of Auxin response factor 1 (ARF1), $\mathrm{ABC}$ transporter $\mathrm{C}$ family member 2 and six serine/threonine-protein kinases (Table S7). Among the genes under putative selection in argyrosperma, we found transcription factor MYB44, Glycerophosphodiester phosphodiesterase GDPDL4, auxin-responsive protein IAA27, WRKY transcription factor 2 (WRKY2), ABC transporter $\mathrm{E}$ family member 2, Filament-like plant protein 4 (FPP4), the ATP-dependent zinc metalloprotease FTSH11, DMR6-like oxygenase 1 (DLO1) and serine/threonine-protein kinase CES101 (Table S7). We also found genes under putative selection overlapping ABBA and BABA sites (Table S7). We found a homolog of flowering locus $\mathrm{K}$ (FLK) under putative selection in argyrosperma and as an ABBA site. We also found a transport inhibitor response 1 (TIR1) homolog under putative selection in both sororia and as a BABA site.

After performing a Gene Ontology enrichment analysis (Alexa et al., 2006), we found seven significantly enriched biological and biochemical processes in the 125 candidate genes, including abscisic acid (ABA) biosynthesis and brassinosteroid- 
mediated signaling (Table S8). The zeaxanthin epoxidase activity was also significantly enriched in the 125 candidate genes (Table S8).

We identified 79 candidate SNPs that resided within 59 of the SVs found between the genome assemblies of sororia and argyrosperma (Table S9). Of these SVs, 10 correspond to putative selective signals in argyrosperma, suggesting they could be associated with its domestication. One CNV gain contains four long noncoding RNAs and additional copies of the mitochondrial genes COX3, ND2 and YMF19. Another CNV contains the gene MKP1, which was found under putative selection in both argyrosperma as a copy loss and in sororia as a copy gain. A third SV consists of a translocation containing an uncharacterized protein. Interestingly, the rest of these domestication SVs only contain long noncoding RNAs (two CNVs and one unaligned region containing 9 long noncoding RNAs), tRNAs (one CNV with 5 tRNAs), or intergenic DNA (two translocations and one CNV). We also found three SVs corresponding to ABBA sites that represent putative introgression signals between argyrosperma and C. moschata. One SV is a CNV that contains an additional copy of a Ras-related protein Rab7 near its candidate SNP (which was identified as an outlier by both PCAdapt and BayeScEnv), another is a translocation that contains the non-specific lipid-transfer protein AKCS9 near its candidate SNP, and the third is an unalignable region containing tRNAs.

\section{Discussion}

The genome assembly of sororia represents the first sequenced genome of a wild Cucurbita, which allowed us to detect structural and functional differences with the argyrosperma genome. The genome assembly of argyrosperma was smaller than the sororia assembly, which is possibly caused by the loss of structural variants during its domestication, as has been reported in pan-genome studies (Khan et al., 2020). Many of these unaligned regions contain entire genes in sororia, making this wild taxon a reservoir of potentially adaptive presence/absence variants. However, the extant genetic diversity of argyrosperma is similar to that of sororia, 
which suggests that the effects of the domestication bottleneck were alleviated by the current gene flow between both subspecies as suggested by our coalescent simulations and by the results of previous studies (Montes-Hernandez and Eguiarte, 2002). This gene flow may be related to the sympatric distribution of the wild and domesticated populations of $C$. argyrosperma throughout the Pacific Coast of Mexico (Sánchez-de la Vega et al., 2018), where their coevolved pollinator bees Peponapsis spp. and Xenoglossa spp. are found (Wilson, 1990). Traditional agricultural practices are another fundamental force that maintains the diversity of crop species (Jarvis et al., 2008). Since argyrosperma is a traditional crop cultivated for both self-supply and local markets where it has a specialized gastronomic niche (Lira et al., 2016), the genetic diversity in argyrosperma is also maintained by the conservation of local landrace varieties at local scales (MontesHernández et al., 2005; Barrera-Redondo et al., 2020).

Our demographic analyses suggest that the extant populations from Jalisco are the closest modern relatives of the initial population of sororia from which argyrosperma originated. The genetic relatedness between the sororia populations from Western Mexico and argyrosperma was also observed with mitochondrial markers (Sanjur et al., 2002). The domestication of $C$. argyrosperma likely started around 8,700 years ago, as suggested by the earliest, albeit taxonomically ambiguous, archaeological record of argyrosperma (Piperno et al., 2009; Ranere et al., 2009). Since crop domestication in Mesoamerica is linked to migration patterns and cultural development of early human populations in America (Zizumbo-Villarreal and Colunga-GarcíaMarín, 2010; Zizumbo-Villarreal et al., 2012), we expected argyrosperma to share historical demographical patterns with human history. Our data shows that the argyrosperma populations found in Guerrero and Jalisco are the most closely related to the sororia populations from Jalisco. This means that even if the closest wild relatives of argyrosperma are currently found in Jalisco, the domestication process may have occurred throughout the lowlands of Jalisco and the Balsas basin (Piperno et al., 2009). Ancient human migration events have been proposed to occur along the river 
basins in Southwestern Mexico, which may explain the genetic cohesiveness among the argyrosperma populations of that area that represent the first fully domesticated lineage of the species (Zizumbo-Villarreal and ColungaGarcíaMarín, 2010). Previous studies based on 8,700 years old phytoliths found in Xihuatoxtla, Guerrero, suggest the co-occurrence of Zea mays and $C$. argyrosperma in the Balsas region within this time period (Piperno et al., 2009; Ranere et al., 2009). Overall, the patterns of genetic structure for $C$. argyrosperma are coherent with the archaeological evidence of early human migration throughout Mesoamerica (Stinnesbeck et al., 2017; Piperno, 2011) (Fig. 6).

We found several signals of putative selection between argyrosperma and sororia, even though tGBS sequencing has a limited capacity to detect selective sweeps across the genome (Lowry et al., 2017). The SNP density for our selection tests was of 44 SNPs per Mb, which is one order of magnitude denser than other studies using reduced-representation genome sequencing to detect selective sweeps (Lowry et al., 2017). This is a consequence of the relatively small genome size of C. argyrosperma (Barrera-Redondo et al., 2019). Nonetheless, the LD in C. argyrosperma decays at a shorter length than our SNP density, so our genome scans should be interpreted as a partial representation of the selective sweeps associated with the domestication process (Lowry et al., 2017).

Most of the putative selective signals were attributed to sororia, probably because wild taxa are subject to many natural selective pressures. Many of the SNPs that were retrieved as outliers were found on genes involved in biotic and abiotic plant defense responses. For example, PBL10 and PBL23 have been suggested to be involved in plant defense pathways due to their similarity to other serine/threonineprotein kinases (Zhang et al., 2010).

However, we also found some genes under putative selection in argyrosperma that could be attributed to defense mechanisms such as MYB44 and DLO1, involved in several defense responses (Shim and Choi, 2013; Zeilmaker et al., 2015); heat response with FTSH11 (Chen et al., 2006); and trichome morphogenesis and 
differentiation with FPP4 and GDPDL4 (Hayashi et al., 2008; Chen et al., 2016), which is a morphological characteristic that differentiates argyrosperma from sororia (Fig. 1). This is concordant with previous studies showing that selective pressures during domestication actively purge these defense mechanisms, as the products of these responses are usually unpleasant or harmful to humans when the plant is consumed (Moreira et al., 2018). This is particularly important for breeding programs, since wild Cucurbita such as sororia harbor loci associated to disease resistance that their domesticated counterparts have lost (Paris, 2016). The selective pressures found in MKP1 suggest a disruptive selection regime between sororia and argyrosperma. Since MKP1 modulates defense responses (UIm et al., 2002), it is possible that both subspecies adapted to differential environmental pressures as domestication took place.

Our Gene Ontology enrichment analysis found several genes enriched in the ABA biosynthesis and brassinosteroid-mediated signaling. This suggests that the alteration of growth hormones may play an important role in $C$. argyrosperma domestication. ABA is involved in a myriad of functions, such as the regulation of plant growth, plant development, seed dormancy and response to biotic/abiotic stress (Chen et al., 2020). In this sense, the lack of dormancy in seeds and gigantism are both common domestication changes that are present in domesticated cucurbits that may be caused by changes in the regulation of $A B A$ and brassinosteroids (Martínez et al., 2017; Chomicki et al., 2019). Particularly, phytohormone regulation may be involved in Cucurbita fruit size alongside microtubule-related genes (Chomicki et al., 2019), such as the microtubuleassociated proteins we found in our structural variant analysis. We found WRKY2 among our candidate genes, which is involved in seed germination and postgermination development in A. thaliana (Jiang and $\mathrm{Yu}, 2009$ ) and may explain the lack of seed dormancy in argyrosperma. Likewise, we found IAA27 under selection in argyrosperma, which is involved in plant growth and development (Liscum and Reed, 2002). 
Among specific candidate genes, we found two ABC transporters under selection in both argyrosperma and sororia. Some $\mathrm{ABC}$ transporters are involved in the transmembrane transport of $\mathrm{ABA}-\mathrm{GE}$, an ABA conjugate that is usually attributed to the plant response against water stress (Burla et al., 2013). However, previous studies in Hordeum vulgare suggest that the transport of ABA-GE may play a role in seed development alongside de novo ABA synthesis within the developing seed (Seiler et al., 2011), suggesting a role of $A B C$ transporters in the seed development of $C$. argyrosperma. Previous studies have also identified an association between variants in $\mathrm{ABC}$ transporter proteins and seed size in Cucurbita maxima (Wang et al., 2019) and Linum usitatissimum (Guo et al., 2019), further suggesting that ABA may be deregulated via selective pressures on $A B C$ transporters to enhance seed size in $C$. argyrosperma during its domestication. Variants in a serine/threonineprotein kinase, as the ones we found in our selective scans, have also been associated with seed size in C. maxima (Wang et al., 2019). We found SPP as a CNV loss in argyrosperma, whose ortholog in C. maxima has been predicted as a major QTL for seed length (Wang et al., 2019). We also detected a significant enrichment of zeaxanthin epoxidase activity. Zeaxanthin epoxidase is linked to the degradation of carotenoids in plant seeds (Gonzalez-Jorge et al., 2016), which in turn are important precursors of ABA biosynthesis, regulating processes such as germination and maturation (Frey et al., 2006).

We found shared derived variants between C. moschata and argyrosperma under putative selection. We located $F L K$, which is involved in flowering time regulation (Mockler et al., 2004), under selection in argyrosperma and as an ABBA site (i.e., as a putatively introgressed allele between both domesticated taxa). We also found Rab7 and AKCS9 within ABBA-related SVs, which are involved in processes such as plant growth and seed development (Cui et al., 2014; Liu et al., 2015). This suggests that, given the close relationship between $C$. argyrosperma and $C$. moschata, both species may share domestication loci involved in common domestication traits such as flowering time, plant growth and seed growth. However, we also found TIR1 under selection in sororia and as a BABA site, which 
is an auxin receptor involved in ethylene signaling and antibacterial resistance in roots (Navarro et al., 2006). These ABBA and BABA sites under selection may be shared with C. moschata either due to incomplete lineage sorting or by adaptive introgression with the wild and domesticated populations of $C$. argyrosperma. The incorporation of domesticated loci between argyrosperma and $C$. moschata through introgression may have been an effective way for Mesoamerican cultures to domesticate multiple Cucurbita taxa. This hypothesis is supported by the significant amount of ABBA sites we found between the genomes of argyrosperma and $C$. moschata. However, this hypothesis needs to be further addressed using population-level data of C. moschata and other domesticated Cucurbita species.

\section{Methods}

\section{Genome assembly and annotation of Cucurbita argyrosperma subsp. sororia}

We sequenced and assembled de novo the genome of a sororia individual collected in Puerto Escondido (Oaxaca, Mexico). Its DNA was extracted from leaf tissue and sequenced using PacBio Sequel at the University of Washington PacBio Sequencing Services and using Illumina HiSeq4000 at the Vincent J. Coates Genomics Sequencing Laboratory in UC Berkeley (NIH S10 Instrumentation Grants S10RR029668 and S10RR027303). We filtered the Illumina sequences using the qualityControl.py script (https://github.com/Czh3/NGSTools) to retain the reads with a PHRED quality $\geq 30$ in $85 \%$ of the sequence and an average PHRED quality $\geq 25$. The Illumina adapters were removed using SeqPrep (https://github.com/jstjohn/SeqPrep) and the paired reads that showed overlap were merged. The chloroplast genome was assembled using NOVOplasty (Dierckxsens et al., 2017) and the organellar reads were filtered using Hisat2 (Kim et al., 2019) against the chloroplast genome of argyrosperma (Barrera-Redondo et al., 2019) and the mitochondrial genome of $C$. pepo (Alverson et al., 2010). We assembled the nuclear genome into small contigs 
using the Illumina reads and the Platanus assembler (Kajitani et al., 2014). The Platanus contigs were assembled into larger contigs using the PacBio Sequel reads and DBG2OLC (Ye et al., 2016). We performed two iterations of minimap2 and racon ( $\mathrm{Li}, 2018$ ) to obtain a consensus genome assembly by mapping the PacBio reads and the Platanus contigs against the DBG2OLC backbone. We performed three additional polishing steps using PILON (Walker et al., 2014) by mapping the Illumina reads against the consensus genome assembly with BWA mem (Li and Durbin, 2010).

The genome annotation processes were performed using the GenSAS v6.0 online platform (Humann et al., 2019). The transposable elements within the genome were predicted and masked using RepeatModeler (http://www.repeatmasker.org/RepeatModeler/). We downloaded five RNA-seq libraries of $C$. argyrosperma available on the Sequence Read Archive (accessions SRR7685400, SRR7685404 - SRR7685407) to use them as RNA-seq evidence for the gene prediction. We performed the same quality filters described above for the RNA-seq data and aligned the high-quality reads against the masked genome of $C$. argyrosperma subsp. sororia using STAR v2.7 (Dobin et al., 2013). We used filterBAM from the Augustus repository (Stanke et al., 2006) to filter low-quality alignments and used the remaining alignments as RNA-seq evidence to predict the gene models using BRAKER2 (Hoff et al., 2016). The gene predictions were functionally annotated using InterProScan (Jones et al., 2014) and by aligning the gene models against the SwissProt database (Schneider et al., 2009) using BLASTp (Camacho et al., 2009) with an e-value $<1 e^{-6}$.

\section{Anchoring the reference genomes into pseudomolecules}

We aimed to improve the genome assembly of argyrosperma, which was previously assembled in 920 scaffolds (Barrera-Redondo et al., 2019), and reach chromosome-level assemblies for both genomes. Thus, we generated Pacbio corrected reads from the published PacBio RSII reads of argyrosperma (NCBI SRA accession SRR7685401) and the PacBio Sequel reads of sororia (sequenced 
for this study at the University of Washington PacBio Sequencing Services) using CANU (Koren et al., 2017). We anchored the genome assemblies of argyrosperma (Barrera-Redondo et al., 2019) and sororia into pseudomolecules using RaGOO (Alonge et al., 2019) alongside the PacBio corrected reads of each taxon to detect and correct misassemblies, using a gap size of $2600 \mathrm{bp}$ for chromosome padding (corresponding to the average gap length of the argyrosperma genome assembly) and using the genome assembly of $C$. moschata (Sun et al., 2017) as reference. The chromosome numbers in both assemblies were assigned in correspondence to the genome assembly of $C$. moschata (Sun et al., 2017).

\section{Structural variant analysis}

We evaluated the synteny between Cucurbita genomes using Synmap2 (HaugBaltzell et al., 2017). We analyzed the genome rearrangements and structural variants between sororia and argyrosperma using Smash (Pratas et al., 2015) with a minimum block size of $100,000 \mathrm{bp}$, a threshold of 1.9 and a context of 28; and using SyRI (Goel et al., 2019) alongside nucmer (Kurtz et al., 2004) with a minimum cluster length of $500 \mathrm{bp}$, an alignment extension length of $500 \mathrm{bp}$, a minimum match length of $100 \mathrm{bp}$ and a minimum alignment identity of $90 \%$. The gene content associated with each type of structural variant was considered either as the overlap between genes and variants (inversions and translocations) or as the genes contained entirely within the structural variants (copy-number variants and unaligned regions). We performed a Gene Ontology enrichment analysis using topGO and the weight01 algorithm (Alexa et al., 2006) to find enriched biological functions associated to each type of structural variant. We determined the significantly enriched biological functions by performing Fisher's exact test ( $p$ value $<0.05)$.

\section{Data filtering and SNP genotyping}

We used previously collected seeds from 19 populations of argyrosperma landraces, four populations of sororia, and three feral populations (Sánchez-de la 
Vega et al., 2018), covering most of the reported distribution of this species throughout Mexico (Castellanos-Morales et al., 2018) (Table S3). The seeds were germinated in a greenhouse and total DNA was extracted from fresh leaves using a DNeasy Plant MiniKit (Qiagen) of 192 individuals across the collected populations (Table S3), including five individuals of $C$. moschata to be used as outgroup. All 192 individuals were sequenced by Data2Bio LLC using the tunable Genotyping by Sequencing (tGBS) method (Ott et al., 2017) with an Ion Proton instrument and two restriction enzymes (Sau3Al/BfuCl and Nspl). The wild and domesticated populations were randomly assigned to the plate wells before library preparation to avoid sequencing biases.

The raw reads of the tGBS sequencing were trimmed using LUCY2 (Li and Chou, 2004), removing bases with PHRED quality scores < 15 using overlapping sliding windows of 10bp. Trimmed reads shorter than $30 \mathrm{bp}$ were discarded. The trimmed reads were mapped against the chromosome-level genome assembly of argyrosperma using segemehl (Hoffmann et al., 2009), since empirical studies suggest this read-mapping software outperforms others for lon Torrent reads (Caboche et al., 2014). We only retained the reads that mapped uniquely to one site of the reference genome for subsequent analyses.

We used BCFtools ( $\mathrm{Li}$ et al., 2009) for an initial variant calling step, retaining variants with at least 6 mapped reads per individual per site where the reads had a minimum PHRED quality score of 20 in the called base and a minimum mapping quality score of 20 (Li et al., 2008). We used plink (Purcell et al., 2007) to perform additional filters, such as retaining only biallelic SNPs, retaining SNPs with no more than $50 \%$ of missing data, individuals with no more than $50 \%$ of missing data and sites with a minor allele frequency (MAF) of at least 1\% (13k dataset). After eliminating individuals with missing data, only 109 individuals of argyrosperma, 44 individuals of sororia, 14 feral individuals and 5 individuals of $C$. moschata remained for the subsequent analyses. We repeated the SNP prediction using the reference genome of sororia to evaluate potential reference biases. We found a 
similar number of SNPs $(10,990)$ and comparable estimates of genetic diversity (see Table S4), suggesting that reference bias does not have a meaningful impact on our results. Thus, we employed the domesticated genome as the reference for the rest of the population analyses.

In order to obtain an adequate SNP dataset to infer the demographic history of $C$. argyrosperma, we performed additional filters to the 13k dataset with plink (Purcell et al., 2007), including the elimination of all the SNPs that diverged significantly ( $p$ $<0.01$ ) from the Hardy-Weinberg equilibrium exact test (Wigginton et al., 2005), and the elimination of adjacent SNPs with a squared correlation coefficient $\left(r^{2}\right)$ larger than 0.25 within $100 \mathrm{kbp}$ sliding windows with a step size of $100 \mathrm{bp}$.

We also generated a SNP dataset to detect selective sweeps associated with the domestication of $C$. argyrosperma by eliminating all the feral individuals of $C$. argyrosperma, which could not be assigned to either a wild or a domesticated population, as well as the five individuals of $C$. moschata. We also eliminated the SNP sites with more than $50 \%$ missing data and performed a MAF filter of $1 \%$ after reducing the number of individuals in the $13 \mathrm{k}$ dataset. The SNP density was calculated with VCFtools (Danecek et al., 2011) and the LD decay was calculated using plink (Purcell et al., 2007) with a minimum $r^{2}$ threshold of 0.001.

We also sequenced the genome of a $C$. moschata individual from Chiapas (Mexico) and the genome of a C. okeechobeensis subsp. martinezii individual from Coatepec (Veracruz, Mexico) using the Illumina HiSeq4000 platform in UC Berkeley. We downloaded the genome sequences of argyrosperma (BarreraRedondo et al., 2019) from the Sequence Read Archive (accessions SRR7685402 and SRR7685403). The Illumina whole-genome sequences were filtered using the same quality parameters as the ones used in the genome assembly of sororia (see above) and were aligned against the chromosome-level assembly of argyrosperma using BWA mem (Li and Durbin, 2010). We only retained the reads that mapped uniquely to one site of the reference genome and retained only the biallelic sites with a sequencing depth $>=10$ reads per genome. 


\section{Population structure}

We used diveRsity (Keenan et al., 2013) to calculate the pairwise FST statistics, using 100 bootstraps to calculate the $95 \%$ confidence intervals. We estimated the genetic variation in the wild, domesticated and feral populations with STACKS (Catchen et al., 2013). Using ADMIXTURE (Alexander et al., 2009), we evaluated the genetic structure among the sororia and argyrosperma populations, evaluating their individual assignment into one (CV error $=0.26205)$, two (CV error $=0.25587)$, three $(C V$ error $=0.25806)$ and four $(C V$ error $=0.26658)$ genetic groups $(K)$. We reconstructed a neighbor-joining maximum-likelihood tree with SNPhylo (Lee et al., 2014), based on genetic distances between all the individuals with 100 bootstraps to assess the reliability of the tree topology. We used plink (Purcell et al., 2007) to perform a principal component analysis (PCA) using 10 principal components.

\section{Coalescent simulations}

We used coalescent simulations to test two different possible scenarios of divergence between the genetic groups observed in our ADMIXTURE and SNPhylo results. In the first scenario, argyrosperma descends from the sororia populations from Jalisco and the sororia populations from Southern Mexico coalesced with the sororia populations from Jalisco. In the second scenario, argyrosperma descends from the sororia populations from Southern Mexico and the sororia populations from Jalisco coalesced with the sororia populations from Southern Mexico. In addition, we also tested for each scenario of domestication whether divergence occurred in the presence of continuous gene flow, gene flow after secondary contact, or in the absence of gene flow.

We used Fastsimcoal 2 (Excoffier and Foll, 2011) to determine the parameters that maximize the composite likelihood of each model given the unfolded multidimensional SFS. The unfolded multidimensional SFS was obtained with DADI (Gutenkunst et al., 2009), using 17 sororia individuals of Jalisco, 27 sororia 
individuals of Southern Mexico, 109 argyrosperma individuals and 5 C. moschata individuals as an outgroup to unfold the SFS. We ran 100,000 simulations with 20 replicates for each model (two divergence scenarios and three gene flow scenarios) using the following settings: a parameter estimation by Maximum Likelihood with a stopping criterion of 0.001 difference between runs, a minimum SFS count of 1 , a maximum of 40 loops to estimate the SFS parameters and a maximum of 200,000 simulations to estimate the SFS parameters. We also selected log-uniform priors for parameter estimations, setting times of divergence between 1000 and 200,000 generations (domestication times are expected to fall within this interval, given that the presumed most ancient evidence of human presence in America is 33,000 years old (Ardelean et al., 2020)), effective population sizes $\left(N_{e}\right)$ between 100 and 60,000 individuals and migration rates $(\mathrm{m})$ between 0.0001 and 0.5 . The 20 replicates of each model converged to similar likelihoods, indicating that the simulations performed well. After corroborating that all replicates converged to similar likelihoods, we combined all replicates and retained all outputs that were above the $95 \%$ of the likelihood distribution. We found that the Jalisco model of divergence with secondary contact had the lowest Akaike Information Criterion values for all the tested models.

\section{Tests to detect selective sweeps and introgression}

We used BayeScEnv (de Villemereuil and Gaggiotti, 2015) to detect putative regions under selection that were differentiated between sororia and argyrosperma. For the "environmental" values used by BayeScEnv, we assigned each population as either wild (0) or domesticated (1). We ran two independent MCMC analyses with 20 initial pilot runs with a length of 10,000 generations and a main run with an initial burn-in of 100,000 generations and a subsequent sampling step for 100,000 generations sampling every 20 generations. We confirmed the convergence between both chains using the Gelman and Rubin statistic (Gelman and Rubin, 1992). The SNPs with $q$-values $<0.05$ were regarded as candidate loci under selection. 
The Mahalanobis distances implemented in PCAdapt (Luu et al., 2017) were used to detect candidate SNPs after controlling for the first two principal components in our dataset, which correspond to the subspecies and geographical differentiation observed among the populations (see Fig. S2). We performed Bonferroni corrections to adjust the $p$-values obtained from PCAdapt and the SNPs with Bonferroni corrected $p$-values $<0.05$ were regarded as candidate loci under selection.

We performed an ABBA-BABA test using Dsuit (Malinsky et al., 2020) against the $11,498,421$ whole-genome variants to evaluate signals of introgression or incomplete lineage sorting between argyrosperma, sororia and C. moschata, while using $C$. okeechobeensis subsp. martinezii as an outgroup. We calculated the $D$ statistic throughout the entire genome within 500 SNP windows with a step size of 250 SNPs. We also used the five tGBS data of $C$. moschata, as well as the wholegenome sequences of $C$. moschata and $C$. okeechobeensis subsp. martinezii, to define the ancestral state of each candidate locus and determine the direction of the selective signals.

We used snpEff (Cingolani et al., 2012) to associate the candidate loci found in both tests with the genome annotation of argyrosperma (Barrera-Redondo et al., 2019). The genes that could be unambiguously assigned to a candidate SNP (the SNP resided within the gene structure, including introns, exons and UTRs) were screened for a Gene Ontology enrichment analysis using topGO and the weight01 algorithm (Alexa et al., 2006). We determined the significantly enriched biological functions by performing a Fisher's exact test ( $p$-value $<0.05)$.

\section{Accession numbers}

The chromosome-level genome assemblies of $C$. argyrosperma subsp. argyrosperma and $C$. argyrosperma subsp. sororia are available at the Cucurbit Genomics Database (Zheng et al., 2019) and in the NCBI RefSeq database (accessions $X X X X X X X X X)$. The raw sequencing reads of the $C$. 
argyrosperma subsp. sororia, C. moschata and C. okeechobeensis subsp. martinezii genomes are available in the NCBI Sequence Read Archive (accessions SRPXXXXXX- SRPXXXXXX). The raw sequencing reads of each individual sequenced by tGBS are available in the NCBI Sequence Read Archive (accessions SRPXXXXXX- SRPXXXXXX; table S3). The 13k SNP dataset is available in Dataset $S 1$ and the $11,498,421$ variant dataset is available in Dataset S2.

\section{Funding}

This work was funded by CONABIO KE004 "Diversidad genética de las especies de Cucurbita en México e hibridación entre plantas genéticamente modificadas y especies silvestres de Cucurbita" and CONABIO PE001 "Diversidad genética de las especies de Cucurbita en México. Fase II. Genómica evolutiva y de poblaciones, recursos genéticos y domesticación" (both awarded to R.L-S. and L.E.E.). J.B-R. is a doctoral student from Programa de Doctorado en Ciencias Biomédicas, Universidad Nacional Autónoma de México, and received fellowship 583146 from CONACyT. G.S-V. is a doctoral student from Programa de Doctorado en Ciencias Biológicas, Universidad Nacional Autónoma de México, and received fellowship 292164 from CONACyT. The population genomic analyses were carried out using CONABIO's computing cluster, which was partially funded by SEMARNAT through the grant "Contribución de la Biodiversidad para el Cambio Climático" to CONABIO.

\section{Author Contributions}

L.E.E., M.I.T., G.S-V. and J.B-R. designed the research; G.S-V. and G.C-M. collected the biological material; G.S-V extracted DNA for the tGBS data; G.C-M. and G.S-V. coordinated the sequencing procedures of the tGBS data; J.B-R. and X.A-D. extracted DNA for reference genome and coordinated its sequencing procedures; E.A-P. coordinated the administrative and lab work; J-B-R., J.A-L. and Y.T.G-G. performed the bioinformatic analyses; G.S-V., J.B-R., J.A-L., M.I.T., and 
L.E.E. analyzed the results; J.B-R., G.S-V. and L.E.E. drafted the manuscript; R.LS. and L.E.E. obtained the funding. All authors revised the final version of the manuscript.

\section{Acknowledgments}

We acknowledge the Doctorado en Ciencias Biomédicas for the support provided during the development of this project. We acknowledge the Doctorado en Ciencias Biológicas for the support provided during the development of this project. We thank Jodi Lynn Humann for her technical support while using the GenSAS web server. Special thanks to Laura Espinosa-Asuar and Silvia Barrientos for their technical support. We thank Rodrigo García Herrera, head of the Scientific Computing Department at LANCIS, Instituto de Ecología UNAM, for running the HTC infrastructure we used for the genome assembly and chromosome anchoring.

\section{References}

Alexa, A., Rahnenführer, J., and Lengauer, T. (2006). Improved scoring of functional groups from gene expression data by decorrelating GO graph structure. Bioinformatics 22:1600-7.

Alexander, D. H., Novembre, J., and Lange, K. (2009). Fast model-based estimation of ancestry in unrelated individuals. Genome Res 19:1655-64.

Alonge, M., Soyk, S., Ramakrishnan, S., Wang, X., Goodwin, S., Sedlazeck, F. J., Lippman, Z. B., and Schatz, M. C. (2019). RaGOO: fast and accurate reference-guided scaffolding of draft genomes. Genome Biol 20:224.

Alverson, A. J., Wei, X., Rice, D. W., Stern, D. B., Barry, K., and Palmer, J. D. (2010). Insights into the evolution of mitochondrial genome size from complete sequences of Citrullus lanatus and Cucurbita pepo (Cucurbitaceae). Mol Biol Evol 27:1436-48. 
Ardelean, C. F., Becerra-Valdivia, L., Pedersen, M. W., Schwenninger, J. L., Oviatt, C. G., Macías-Quintero, J. I., Arroyo-Cabrales, J., Sikora, M., OcampoDíaz, Y. Z. E., Rubio-Cisneros, I. I., et al. (2020). Evidence of human occupation in Mexico around the Last Glacial Maximum. Nature 584: 87-92.

Barrera-Redondo, J., Hernández-Rosales, H. S., Cañedo-Torres, V., Aréstegui-Alegría, K., Torres-Guevara, J., Parra, F., Torres-García, I., and Casas, A. (2020). Landrace diversity and local selection criteria of domesticated squashes and gourds (Cucurbita) in the central Andean mountain range of Peru: Tomayquichua, Huánuco. Botanical Sciences 98:101-116.

Barrera-Redondo, J., Ibarra-Laclette, E., Vázquez-Lobo, A., GutiérrezGuerrero, Y. T., Sánchez, de la V. G., Piñero, D., Montes-Hernández, S., LiraSaade, R., and Eguiarte, L. E. (2019). The genome of Cucurbita argyrosperma (silver-seed gourd) reveals faster rates of rrotein-roding gene and long noncoding RNA turnover and neofunctionalization within Cucurbita. Mol Plant 12:506-520.

Burla, B., Pfrunder, S., Nagy, R., Francisco, R. M., Lee, Y., and Martinoia, E. (2013). Vacuolar transport of abscisic acid glucosyl ester is mediated by ATPbinding cassette and proton-antiport mechanisms in Arabidopsis. Plant Physiol 163:1446-58.

Caboche, S., Audebert, C., Lemoine, Y., and Hot, D. (2014). Comparison of mapping algorithms used in high-throughput sequencing: application to lon Torrent data. BMC Genomics 15:264.

Camacho, C., Coulouris, G., Avagyan, V., Ma, N., Papadopoulos, J., Bealer, K., and Madden, T. L. (2009). BLAST+: architecture and applications. BMC Bioinformatics 10:421.

Castellanos-Morales, G., Paredes-Torres, L. M., Gámez, N., HernándezRosales, H. S., Sánchez-de, la V. G., Barrera-Redondo, J., Aguirre-Planter, E., Vázquez-Lobo, A., Montes-Hernández, S., Lira-Saade, R., et al. (2018). 
Historical biogeography and phylogeny of Cucurbita: Insights from ancestral area reconstruction and niche evolution. Mol Phylogenet Evol 128:38-54.

Catchen, J., Hohenlohe, P. A., Bassham, S., Amores, A., and Cresko, W. A. (2013). Stacks: an analysis tool set for population genomics. Mol Ecol 22:312440.

Chen, J., Burke, J. J., Velten, J., and Xin, Z. (2006). FtsH11 protease plays a critical role in Arabidopsis thermotolerance. The Plant Journal 48:73-84.

Chen, K., Li, G. J., Bressan, R. A., Song, C. P., Zhu, J. K., and Zhao, Y. (2020). Abscisic acid dynamics, signaling, and functions in plants. J Integr Plant Biol 62:25-54.

Chen, L., Peng, Y., Tian, J., Wang, X., Kong, Z., Mao, T., Yuan, M., and Li, Y. (2016). TCS1, a microtubule-binding protein, interacts with $K C B P / Z W I C H E L$ to regulate trichome cell shape in Arabidopsis thaliana. PLoS Genet 12:e1006266.

Chomicki, G., Schaefer, H., and Renner, S. S. (2019). Origin and domestication of Cucurbitaceae crops: insights from phylogenies, genomics and archaeology. New Phytol 226.

Cingolani, P., Platts, A., Wang, le L., Coon, M., Nguyen, T., Wang, L., Land, S. J., Lu, X., and Ruden, D. M. (2012). A program for annotating and predicting the effects of single nucleotide polymorphisms, SnpEff: SNPs in the genome of Drosophila melanogaster strain w1118; iso-2; iso-3. Fly (Austin) 6:80-92.

Cui, Y., Zhao, Q., Gao, C., Ding, Y., Zeng, Y., Ueda, T., Nakano, A., and Jiang, L. (2014). Activation of the Rab7 GTPase by the MON1-CCZ1 Complex is essential for PVC-to-vacuole trafficking and plant growth in Arabidopsis. Plant Cell 26:2080-2097.

Danecek, P., Auton, A., Abecasis, G., Albers, C. A., Banks, E., DePristo, M. A., Handsaker, R. E., Lunter, G., Marth, G. T., Sherry, S. T., et al. (2011). The variant call format and VCFtools. Bioinformatics 27:2156-8. 
Dierckxsens, N., Mardulyn, P., and Smits, G. (2017). NOVOPlasty: de novo assembly of organelle genomes from whole genome data. Nucleic Acids Res 45:e18.

Dobin, A., Davis, C. A., Schlesinger, F., Drenkow, J., Zaleski, C., Jha, S., Batut, P., Chaisson, M., and Gingeras, T. R. (2013). STAR: ultrafast universal RNA-seq aligner. Bioinformatics 29:15-21.

Excoffier, L., and Foll, M. (2011). fastsimcoal: a continuous-time coalescent simulator of genomic diversity under arbitrarily complex evolutionary scenarios. Bioinformatics 27:1332-4.

Frey, A., Boutin, J. P., Sotta, B., Mercier, R., and Marion-Poll, A. (2006). Regulation of carotenoid and $\mathrm{ABA}$ accumulation during the development and germination of Nicotiana plumbaginifolia seeds. Planta 224:622-32.

Gelman, A., and Rubin, D. B. (1992). Inference from iterative simulation using multiple sequences. Statistical Science 7:457-472.

Goel, M., Sun, H., Jiao, W. B., and Schneeberger, K. (2019). SyRI: finding genomic rearrangements and local sequence differences from whole-genome assemblies. Genome Biol 20:277.

Gonzalez-Jorge, S., Mehrshahi, P., Magallanes-Lundback, M., Lipka, A. E., Angelovici, R., Gore, M. A., and DellaPenna, D. (2016). ZEAXANTHIN EPOXIDASE activity potentiates carotenoid degradation in maturing seed. Plant Physiol 171:1837-51.

Guo, D., Jiang, H., Yan, W., Yang, L., Ye, J., Wang, Y., Yan, Q., Chen, J., Gao, Y., Duan, L., et al. (2019). Resequencing 200 flax cultivated accessions identifies candidate genes related to seed size and weight and reveals signatures of artificial selection. Front Plant Sci 10:1682. 
Gutenkunst, R. N., Hernandez, R. D., Williamson, S. H., and Bustamante, C. D. (2009). Inferring the joint demographic history of multiple populations from multidimensional SNP frequency data. PLoS Genet 5:e1000695.

Haug-Baltzell, A., Stephens, S. A., Davey, S., Scheidegger, C. E., and Lyons, E. (2017). SynMap2 and SynMap3D: web-based whole-genome synteny browsers. Bioinformatics 33:2197-2198.

Hayashi, S., Ishii, T., Matsunaga, T., Tominaga, R., Kuromori, T., Wada, T., Shinozaki, K., and Hirayama, T. (2008). The glycerophosphoryl diester phosphodiesterase-like proteins SHV3 and its homologs play important roles in cell wall organization. Plant Cell Physiol 49:1522-35.

Hoff, K. J., Lange, S., Lomsadze, A., Borodovsky, M., and Stanke, M. (2016). BRAKER1: unsupervised RNA-seq-based genome annotation with GeneMark-ET and AUGUSTUS. Bioinformatics 32:767-9.

Hoffmann, S., Otto, C., Kurtz, S., Sharma, C. M., Khaitovich, P., Vogel, J., Stadler, P. F., and Hackermüller, J. (2009). Fast mapping of short sequences with mismatches, insertions and deletions using index structures. PLoS Comput Biol 5:e1000502.

Humann, J. L., Lee, T., Ficklin, S., and Main, D. (2019). Structural and functional annotation of eukaryotic genomes with GenSAS. Methods Mol Biol 1962:29-51.

Jarvis, D. I., Brown, A. H., Cuong, P. H., Collado-Panduro, L., LatournerieMoreno, L., Gyawali, S., Tanto, T., Sawadogo, M., Mar, I., Sadiki, M., et al. (2008). A global perspective of the richness and evenness of traditional cropvariety diversity maintained by farming communities. Proc Natl Acad Sci USA 105:5326-31.

Jiang, W., and Yu, D. (2009). Arabidopsis WRKY2 transcription factor mediates seed germination and postgermination arrest of development by abscisic acid. BMC Plant Biol 9:96. 
Jones, P., Binns, D., Chang, H. Y., Fraser, M., Li, W., McAnulla, C., McWilliam, H., Maslen, J., Mitchell, A., Nuka, G., et al. (2014). InterProScan 5: genomescale protein function classification. Bioinformatics 30:1236-40.

Kajitani, R., Toshimoto, K., Noguchi, H., Toyoda, A., Ogura, Y., Okuno, M., Yabana, M., Harada, M., Nagayasu, E., Maruyama, H., et al. (2014). Efficient de novo assembly of highly heterozygous genomes from whole-genome shotgun short reads. Genome Res 24:1384-95.

Keenan, K., McGinnity, P., Cross, T. F., Crozier, W. W., and Prodöhl, P. A. (2013). diveRsity: An R package for the estimation and exploration of population genetics parameters and their associated errors. Methods in Ecology and Evolution 4:782-788.

Khan, A. W., Garg, V., Roorkiwal, M., Golicz, A. A., Edwards, D., and Varshney, R. K. (2020). Super-pangenome by integrating the wild side of a species for accelerated crop improvement. Trends Plant Sci 25:148-158.

Kim, D., Paggi, J. M., Park, C., Bennett, C., and Salzberg, S. L. (2019). Graphbased genome alignment and genotyping with HISAT2 and HISAT-genotype. Nat Biotechnol 37:907-915.

Kistler, L., Newsom, L. A., Ryan, T. M., Clarke, A. C., Smith, B. D., and Perry, G. H. (2015). Gourds and squashes (Cucurbita spp.) adapted to megafaunal extinction and ecological anachronism through domestication. Proc Natl Acad Sci U S A 112:15107-12.

Koren, S., Walenz, B. P., Berlin, K., Miller, J. R., Bergman, N. H., and Phillippy, A. M. (2017). Canu: scalable and accurate long-read assembly via adaptive $k$-mer weighting and repeat separation. Genome Res 27:722-736.

Kurtz, S., Phillippy, A., Delcher, A. L., Smoot, M., Shumway, M., Antonescu, C., and Salzberg, S. L. (2004). Versatile and open software for comparing large genomes. Genome Biol 5:R12. 
Lee, T. H., Guo, H., Wang, X., Kim, C., and Paterson, A. H. (2014). SNPhylo: a pipeline to construct a phylogenetic tree from huge SNP data. BMC Genomics 15:162.

Li, H. (2018). Minimap2: pairwise alignment for nucleotide sequences. Bioinformatics 34:3094-3100.

Li, H., and Durbin, R. (2010). Fast and accurate long-read alignment with Burrows-Wheeler transform. Bioinformatics 26:589-95.

Li, H., Handsaker, B., Wysoker, A., Fennell, T., Ruan, J., Homer, N., Marth, G., Abecasis, G., and Durbin, R. (2009). The Sequence Alignment/Map format and SAMtools. Bioinformatics 25:2078-9.

Li, H., Ruan, J., and Durbin, R. (2008). Mapping short DNA sequencing reads and calling variants using mapping quality scores. Genome Res 18:1851-8.

Li, S., and Chou, H. H. (2004). LUCY2: an interactive DNA sequence quality trimming and vector removal tool. Bioinformatics 20:2865-6.

Lira, R., Eguiarte, L., Montes, S., Zizumbo-Villarreal, D., Marín, P. C.-G., and Quesada, M. (2016). Homo sapiens-Cucurbita interaction in Mesoamerica: domestication dissemination, and diversification. In Ethnobotany of Mexico, pp. 389-401. Springer New York.

Liscum, E., and Reed, J. W. (2002). Genetics of Aux/IAA and ARF action in plant growth and development. Plant Mol Biol 49:387-400.

Liu, F., Zhang, X., Lu, C., Zeng, X., Li, Y., Fu, D., and Wu, G. (2015). Non-specific lipid transfer proteins in plants: presenting new advances and an integrated functional analysis. Journal of Experimental Botany 66:5663-5681.

Lowry, D. B., Hoban, S., Kelley, J. L., Lotterhos, K. E., Reed, L. K., Antolin, M. F., and Storfer, A. (2017). Responsible RAD: Striving for best practices in population genomic studies of adaptation. Mol Ecol Resour 17:366-369. 
Luu, K., Bazin, E., and Blum, M. G. (2017). pcadapt: an R package to perform genome scans for selection based on principal component analysis. Mol Ecol Resour 17:67-77.

Malinsky, M., Matschiner, M., and Svardal, H. (2020). Dsuite - fast D-statistics and related admixture evidence from VCF files. Mol Ecol Resour Advance Access published 2020.

Martínez, A. B., Lema, V., Capparelli, A., Anido, F. L., Benech-Arnold, R., and Bartoli, C. G. (2017). Differences in seed dormancy associated with the domestication of Cucurbita maxima: elucidation of some mechanisms behind this response. Seed Science Research 28:1-7.

Meyer, R. S., and Purugganan, M. D. (2013). Evolution of crop species: genetics of domestication and diversification. Nat Rev Genet 14:840-52.

Mockler, T. C., Yu, X., Shalitin, D., Parikh, D., Michael, T. P., Liou, J., Huang, J., Smith, Z., Alonso, J. M., Ecker, J. R., et al. (2004). Regulation of flowering time in Arabidopsis by $K$ homology domain proteins. Proc Natl Acad Sci USA 101:12759-12764.

Montes-Hernandez, S., and Eguiarte, L. E. (2002). Genetic structure and indirect estimates of gene flow in three taxa of Cucurbita (Cucurbitaceae) in western Mexico. Am J Bot 89:1156-63.

Montes-Hernández, S., Merrick, L. C., and Eguiarte, L. E. (2005). Maintenance of squash (Cucurbita spp.) landrace diversity by farmers activities in Mexico. Genetic Resources and Crop Evolution 52:697-707.

Moreira, X., Abdala-Roberts, L., Gols, R., and Francisco, M. (2018). Plant domestication decreases both constitutive and induced chemical defenses by direct selection against defensive traits. Sci Rep 8:12678. 
Navarro, L., Dunoyer, P., Jay, F., Arnold, B., Dharmasiri, N., Estelle, M., Voinnet, O., and Jones, J. D. (2006). A plant miRNA contributes to antibacterial resistance by repressing auxin signaling. Science 312:436-9.

Ott, A., Liu, S., Schnable, J. C., Yeh, C., Wang, K. S., and Schnable, P. S. (2017). tGBS® genotyping-by-sequencing enables reliable genotyping of heterozygous loci. Nucleic Acids Res 45:e178.

Paris, H. S. (2016). Genetic resources of pumpkins and squash Cucurbita spp. In Genetics and Genomics of Cucurbitaceae, pp. 111-154. Springer International Publishing.

Piperno, D. R. (2011). The origins of plant cultivation and domestication in the New World Tropics. Current Anthropology 52:S453-S470.

Piperno, D. R., Ranere, A. J., Holst, I., Iriarte, J., and Dickau, R. (2009). Starch grain and phytolith evidence for early ninth millennium B.P. maize from the Central Balsas River Valley, Mexico. Proc Natl Acad Sci U S A 106:5019-24.

Pratas, D., Silva, R. M., Pinho, A. J., and Ferreira, P. J. (2015). An alignmentfree method to find and visualize rearrangements between pairs of DNA sequences. Sci Rep 5:10203.

Purcell, S., Neale, B., Todd-Brown, K., Thomas, L., Ferreira, M. A., Bender, D., Maller, J., Sklar, P., de, B. P. I., Daly, M. J., et al. (2007). PLINK: a tool set for whole-genome association and population-based linkage analyses. Am J Hum Genet 81:559-75.

Ranere, A. J., Piperno, D. R., Holst, I., Dickau, R., and Iriarte, J. (2009). The cultural and chronological context of early Holocene maize and squash domestication in the Central Balsas River Valley, Mexico. Proc Natl Acad Sci U S A 106:5014-8.

Sanjur, O. I., Piperno, D. R., Andres, T. C., and Wessel-Beaver, L. (2002). Phylogenetic relationships among domesticated and wild species of Cucurbita 
(Cucurbitaceae) inferred from a mitochondrial gene: Implications for crop plant evolution and areas of origin. Proc Natl Acad Sci U S A 99:535-40.

Schneider, M., Lane, L., Boutet, E., Lieberherr, D., Tognolli, M., Bougueleret, L., and Bairoch, A. (2009). The UniProtKB/Swiss-Prot knowledgebase and its Plant Proteome Annotation Program. J Proteomics 72:567-73.

Seiler, C., Harshavardhan, V. T., Rajesh, K., Reddy, P. S., Strickert, M., Rolletschek, H., Scholz, U., Wobus, U., and Sreenivasulu, N. (2011). ABA biosynthesis and degradation contributing to ABA homeostasis during barley seed development under control and terminal drought-stress conditions. $J$ Exp Bot 62:2615-32.

Shim, J. S., and Choi, Y. D. (2013). Direct regulation of WRKY70 by AtMYB44 in plant defense responses. Plant Signal Behav 8:e20783.

Simão, F. A., Waterhouse, R. M., loannidis, P., Kriventseva, E. V., and Zdobnov, E. M. (2015). BUSCO: assessing genome assembly and annotation completeness with single-copy orthologs. Bioinformatics 31:3210-2.

Smith, B. D. (1997). Reconsidering the Ocampo caves and the era of incipient cultivation in Mesoamerica. Latin American Antiquity 8:342-383.

Stanke, M., Schöffmann, O., Morgenstern, B., and Waack, S. (2006). Gene prediction in eukaryotes with a generalized hidden Markov model that uses hints from external sources. BMC Bioinformatics 7:62.

Stinnesbeck, W., Becker, J., Hering, F., Frey, E., González, A. G., Fohlmeister, J., Stinnesbeck, S., Frank, N., Terrazas, M. A., Benavente, M. E., et al. (2017). The earliest settlers of Mesoamerica date back to the late Pleistocene. PLoS One 12:e0183345.

Sun, H., Wu, S., Zhang, G., Jiao, C., Guo, S., Ren, Y., Zhang, J., Zhang, H., Gong, G., Jia, Z., et al. (2017). Karyotype stability and unbiased fractionation in the paleo-allotetraploid Cucurbita genomes. Mol Plant 10:1293-1306. 
Sánchez-de la Vega, G., Castellanos-Morales, G., Gámez, N., HernándezRosales, H. S., Vázquez-Lobo, A., Aguirre-Planter, E., Jaramillo-Correa, J. P., Montes-Hernández, S., Lira-Saade, R., and Eguiarte, L. E. (2018). Genetic resources in the calabaza pipiana squash (Cucurbita argyrosperma) in Mexico: genetic diversity, genetic differentiation and distribution models. Front Plant Sci 9:400.

Ulm, R., Ichimura, K., Mizoguchi, T., Peck, S. C., Zhu, T., Wang, X., Shinozaki, K., and Paszkowski, J. (2002). Distinct regulation of salinity and genotoxic stress responses by Arabidopsis MAP kinase phosphatase 1. EMBO J 21:6483-93.

Walker, B. J., Abeel, T., Shea, T., Priest, M., Abouelliel, A., Sakthikumar, S., Cuomo, C. A., Zeng, Q., Wortman, J., Young, S. K., et al. (2014). Pilon: an integrated tool for comprehensive microbial variant detection and genome assembly improvement. PLoS One 9:e112963.

Wang, Y., Wang, C., Han, H., Luo, Y., Wang, Z., Yan, C., Xu, W., and Qu, S. (2019). Construction of a high-density genetic map and analysis of seed-related traits using specific length amplified fragment sequencing for Cucurbita maxima. Front Plant Sci 10:1782.

Whitaker, T. W., and Bemis, W. P. (1975). Origin and evolution of the cultivated Cucurbita. Bulletin of the Torrey Botanical Club 102.

Whitaker, T. W., and Cutler, H. C. (1965). Cucurbits and cultures in the Americas. Economic Botany 19:344-349.

Wigginton, J. E., Cutler, D. J., and Abecasis, G. R. (2005). A note on exact tests of Hardy-Weinberg equilibrium. Am J Hum Genet 76:887-93.

Wilson, H. D. (1990). Gene flow in squash species. BioScience 40:449-455.

Ye, C., Hill, C. M., Wu, S., Ruan, J., and Ma, Z. S. (2016). DBG2OLC: efficient assembly of large genomes using long erroneous reads of the third generation sequencing technologies. Sci Rep 6:31900. 
Zeder, M. A. (2015). Core questions in domestication research. Proc Natl Acad Sci U S A 112:3191-8.

Zeilmaker, T., Ludwig, N. R., Elberse, J., Seidl, M. F., Berke, L., Van, D. A., Schuurink, R. C., Snel, B., and Van, den A. G. (2015). DOWNY MILDEW RESISTANT 6 and DMR6-LIKE OXYGENASE 1 are partially redundant but distinct suppressors of immunity in Arabidopsis. Plant J 81:210-22.

Zhang, J., Li, W., Xiang, T., Liu, Z., Laluk, K., Ding, X., Zou, Y., Gao, M., Zhang, X., Chen, S., et al. (2010). Receptor-like cytoplasmic kinases integrate signaling from multiple plant immune receptors and are targeted by a Pseudomonas syringae effector. Cell Host Microbe 7:290-301.

Zheng, Y., Wu, S., Bai, Y., Sun, H., Jiao, C., Guo, S., Zhao, K., Blanca, J., Zhang, Z., Huang, S., et al. (2019). Cucurbit Genomics Database (CuGenDB): a central portal for comparative and functional genomics of cucurbit crops. Nucleic Acids Res 47:D1128-D1136.

Zizumbo-Villarreal, D., and Colunga-GarcíaMarín, P. (2010). Origin of agriculture and plant domestication in West Mesoamerica. Genetic Resources and Crop Evolution 57:813-825.

Zizumbo-Villarreal, D., Flores-Silva, A., and Marín, P. C.-G. (2012). The archaic diet in Mesoamerica: incentive for milpa development and species domestication. Economic Botany 66:328-343.

de Villemereuil, P., and Gaggiotti, O. E. (2015). A new FSt-based method to uncover local adaptation using environmental variables. Methods in Ecology and Evolution 6:1248-1258. 
bioRxiv preprint doi: https://doi.org/10.1101/2020.10.15.341990; this version posted October 16, 2020. The copyright holder for this preprint (which was not certified by peer review) is the author/funder, who has granted bioRxiv a license to display the preprint in perpetuity. It is made

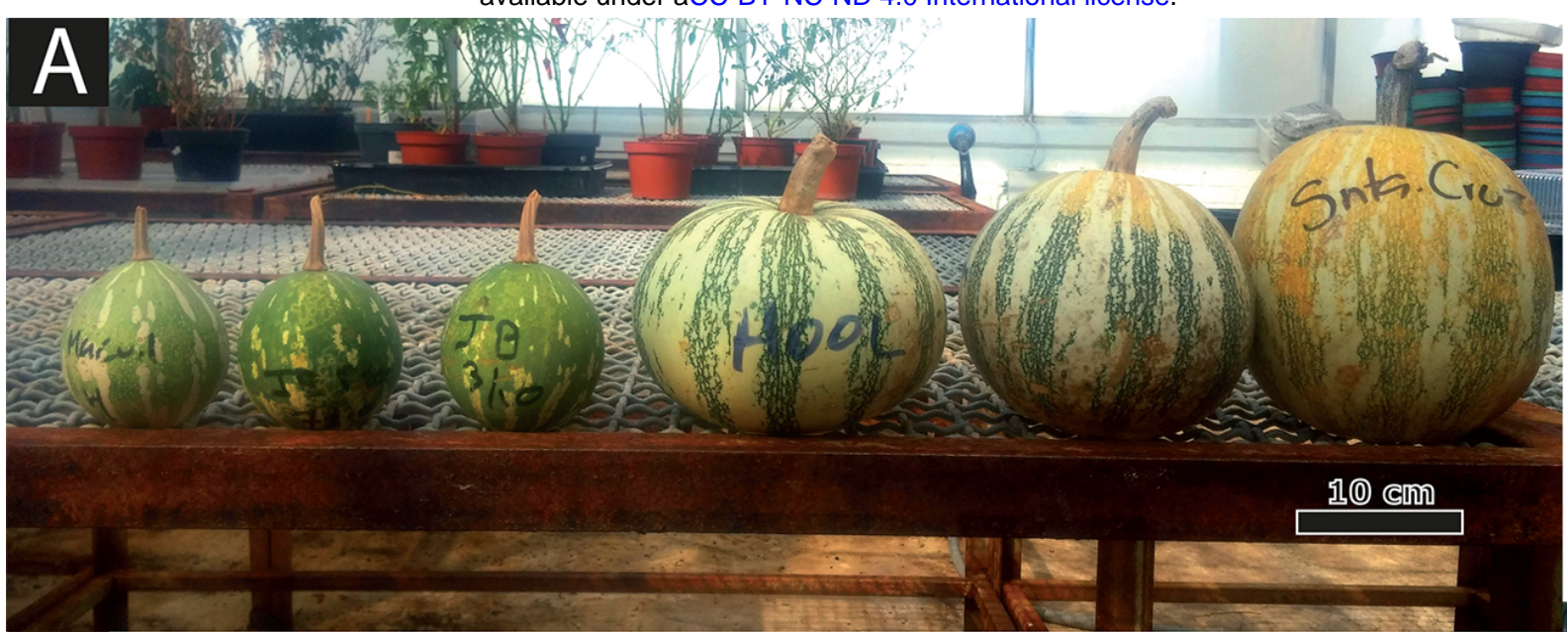

\section{B}

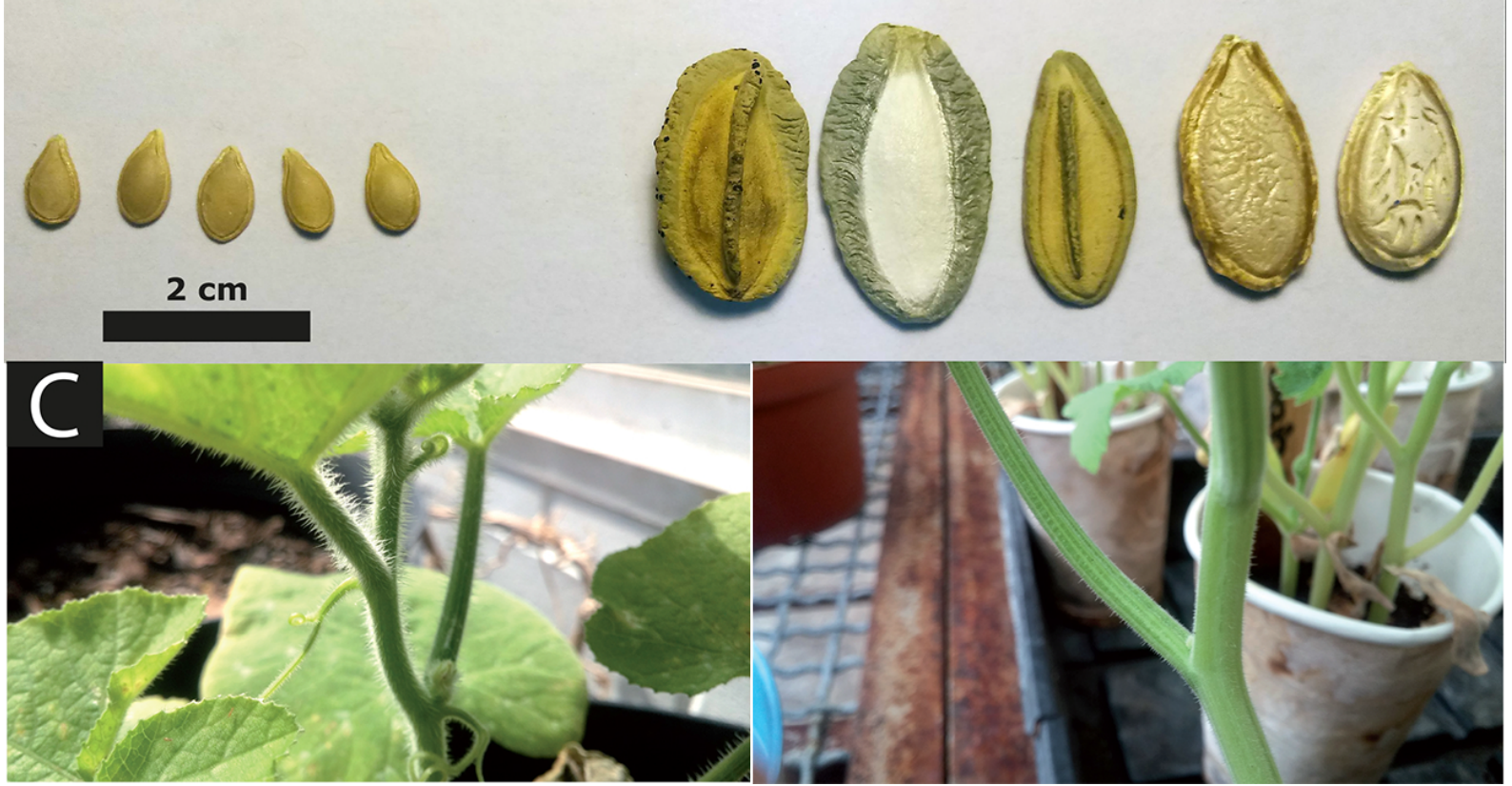

Figure 1. Some morphological differences between C. argyrosperma subsp. sororia (left) and C. argyrosperma subsp. argyrosperma (right). Differences in fruit size (A), seed size and shape $(B)$, and in the presence of urticating trichomes (C). 
bioRxiv preprint doi: https://doi.org/10.1101/2020.10.15.341990; this version posted October 16, 2020. The copyright holder for this preprint (which was not certified by peer review) is the author/funder, who has granted bioRxiv a license to display the preprint in perpetuity. It is made

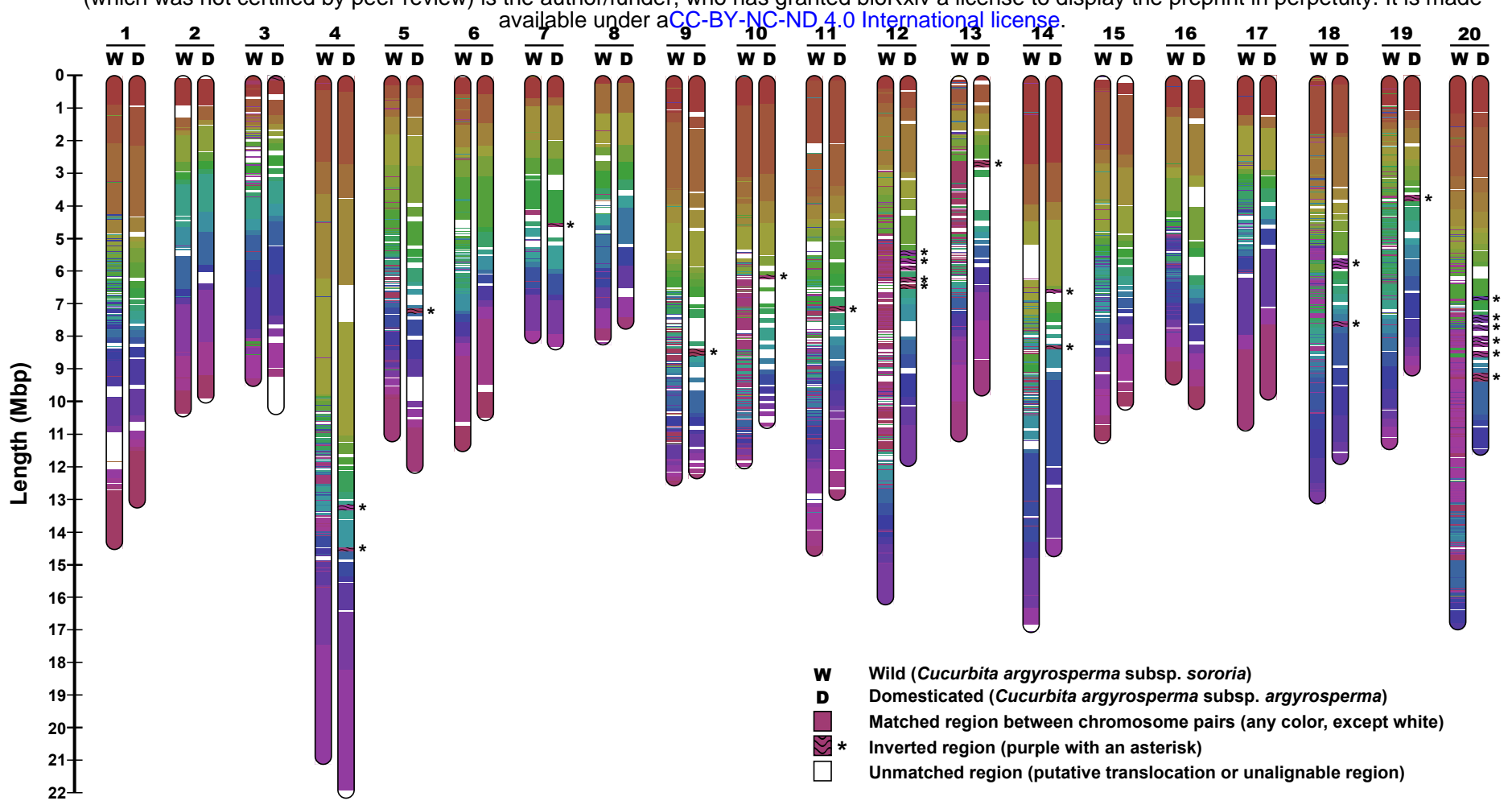

Figure 2. Chromosome map representing the matching regions and putative structural variants between the genome assemblies of $C$. argyrosperma subsp. sororia (wild) and C. argyrosperma subsp. argyrosperma (domesticated). Matching colors represent the aligned homologous regions between both genomes, while white segments represent regions that could not be aligned to the other genome. Inverted regions are highlighted with an asterisk. 
bioRxiv preprint doi: https://doi.org/10.1101/2020.10.15.341990; this version posted October 16, 2020. The copyright holder for this preprint (which was not certified by peer review) is the author/funder, who has granted bioRxiv a license to display the preprint in perpetuity. It is made
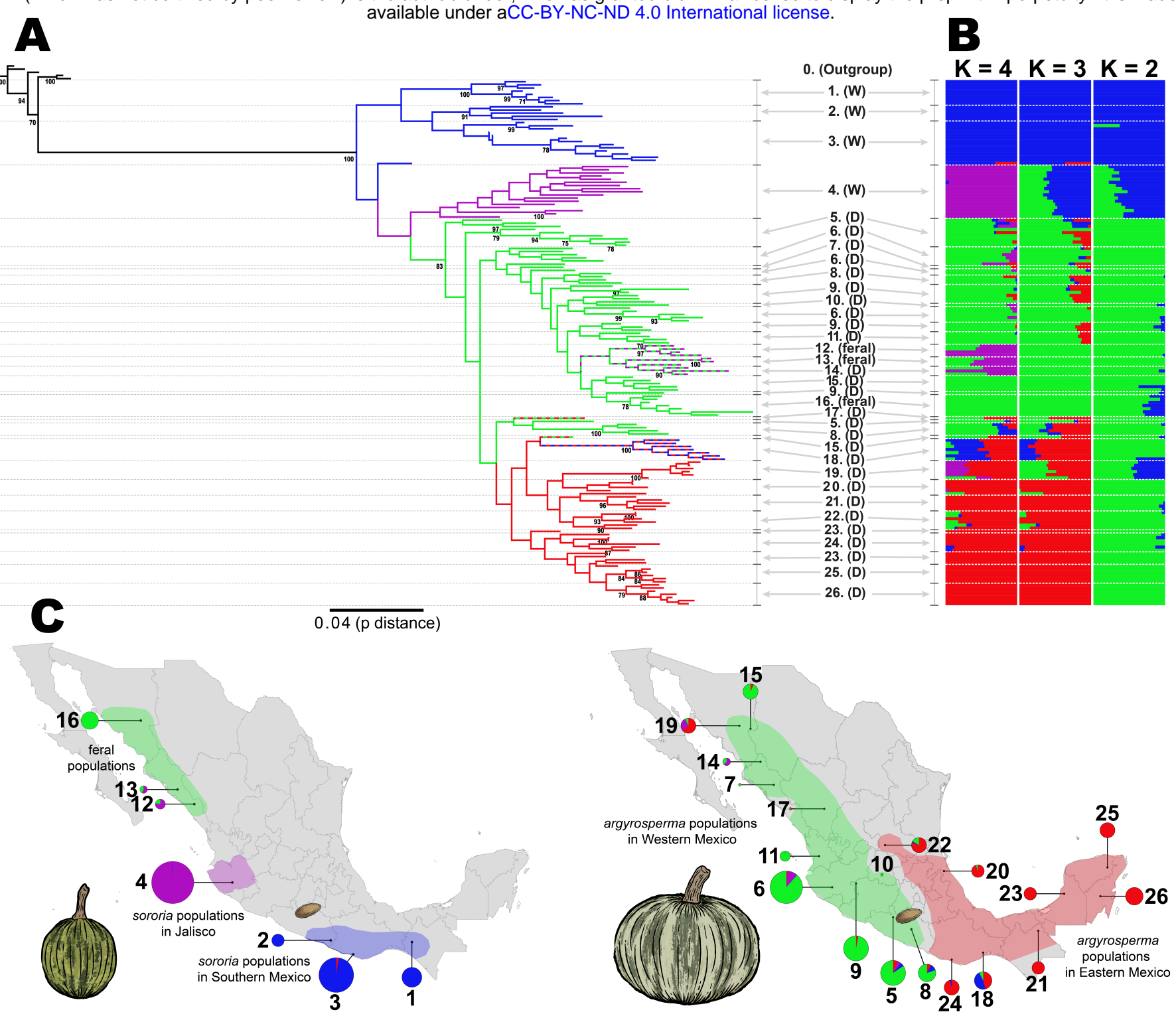

Figure 3. Genetic structure and phylogenetic relationships between the wild and domesticated populations of Cucurbita argyrosperma based on 2,861 SNPs. (A) Maximum Likelihood tree with 100 bootstraps (only bootstrap values > 70 shown) (B) ADMIXTURE analysis using $\mathrm{K}$ values ranging from 2 to 4 . (C) Geographic distribution of the wild (down left) and domesticated (down right) populations, with pie chart colors representing the ADMIXTURE assignation of the individuals in $4 \mathrm{~K}$ ancestral populations (size of pie charts proportional to sample size). The seed in the maps represent the earliest archaeological record of argyrosperma from Xihuatoxtla, Guerrero (dated 8,700 years BP) (Piperno et al., 2009). 
bioRxiv preprint doi: https://doi.org/10.1101/2020.10.15.341990; this version posted October 16, 2020. The copyright holder for this preprint (which was not certified by peer review) is the author/funder, who has granted bioRxiv a license to display the preprint in perpetuity. It is made available under aCC-BY-NC-ND 4.0 International license.

A

Constant gene flow Secondary contact No gene flow
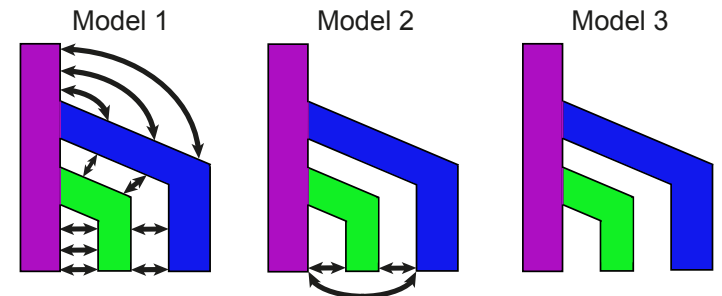

Domestication occurs in Jalisco
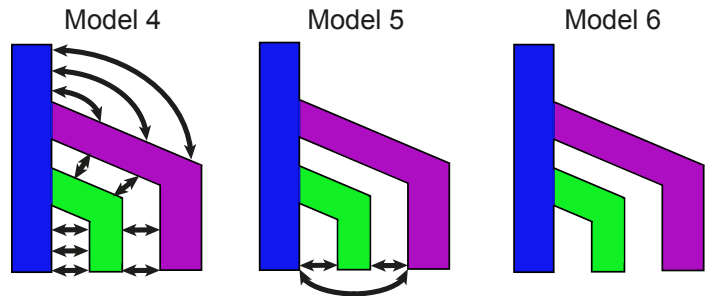

Domestication occurs in Southern Mexico

B

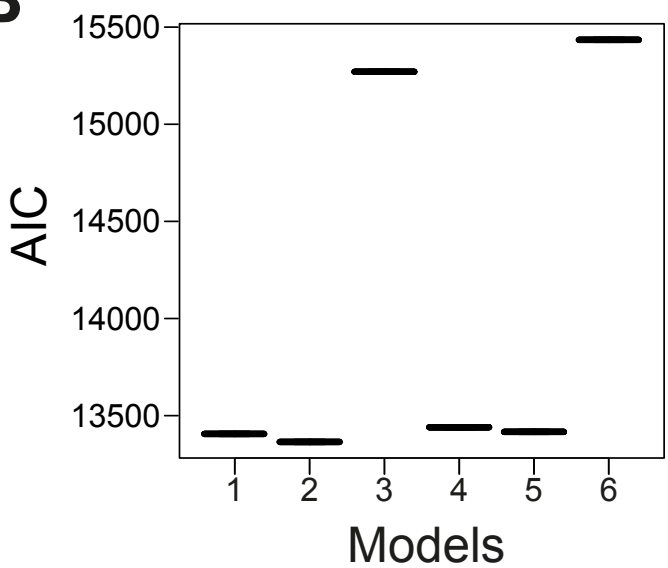

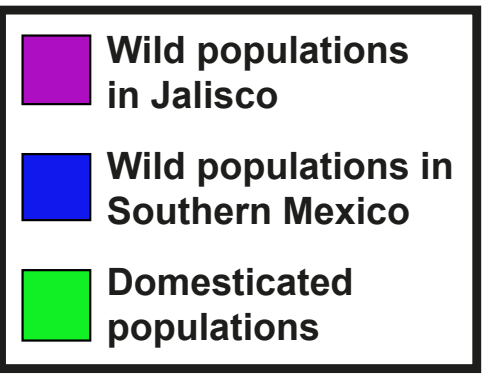

\section{Best model} Domestication in Jalisco with secondary contact

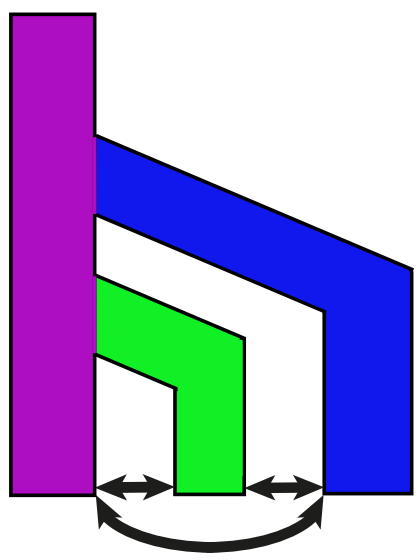

Figure 4. Coalescent simulations and most likely domestication scenario of Cucurbita argyrosperma. (A) The six models assessed against the unfolded multidimensional Site Frequency Spectrum of our data. (B) Comparison of the Akaike Information Criterion (AIC) of all the models. (C) The domestication model that best fits the data. 
bioRxiv preprint doi: https://doi.org/10.1101/2020.10.15.341990; this version posted October 16, 2020. The copyright holder for this preprint (which was not certified by peer review) is the author/funder, who has granted bioRxiv a license to display the preprint in perpetuity. It is made available under aCC-BY-NC-ND 4.0 International license.

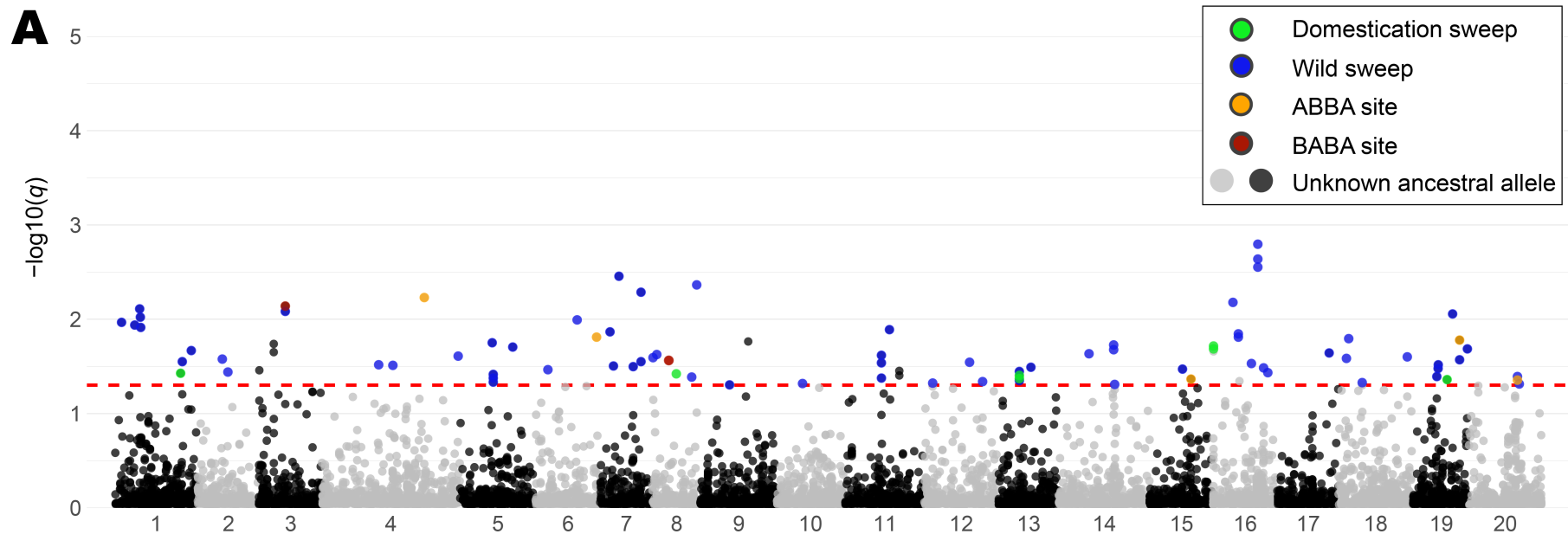

$\mathbf{B}$

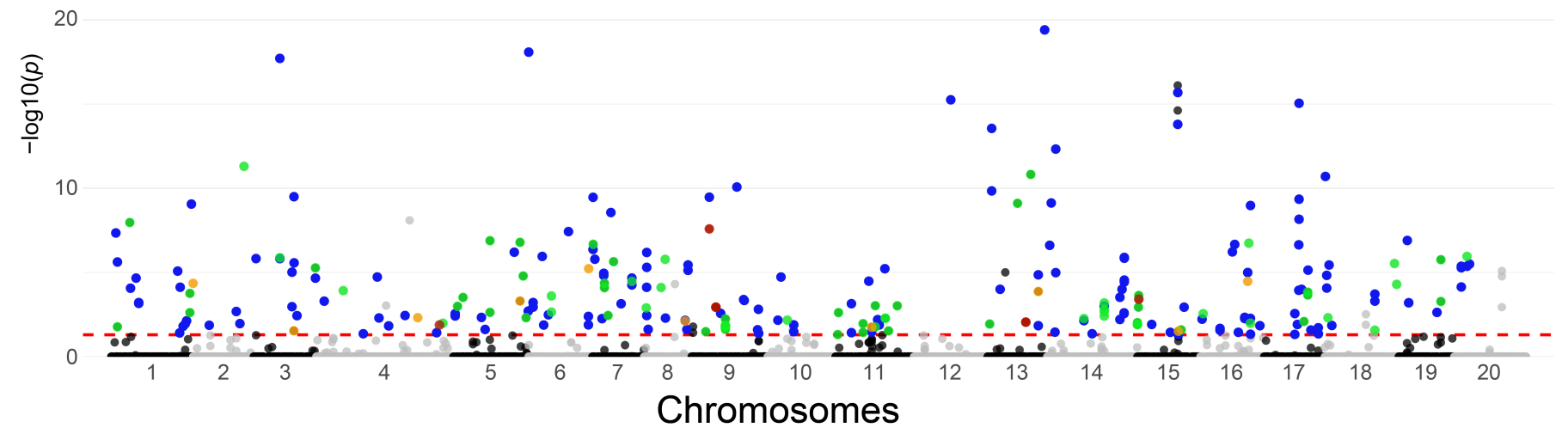

Figure 5. Putative footprints of selection associated with the domestication of Cucurbita argyrosperma. Manhattan plots representing the (A) BayeScEnv and (B) PCAdapt tests in each chromosome of the genome. The red line indicates the cutoff value ( $q$-value or Bonferroni-corrected $p$-value $<0.05)$ to determine a candidate locus. The colors of the outlier loci indicate whether the putative selective signal corresponds to argyrosperma (green), sororia (blue), an ABBA site (orange) a BABA site (red) or an unknown selective direction (grey or black dots above threshold). 
bioRxiv preprint doi: https://doi.org/10.1101/2020.10.15.341990; this version posted October 16, 2020. The copyright holder for this preprint (which was not certified by peer review) is the author/funder, who has granted bioRxiv a license to display the preprint in perpetuity. It is made available under aCC-BY-NC-ND 4.0 International license.

Paleoclimate

Mexican lowlands

Human

subsistence system

Plant domestication stages

Archaeological evidence

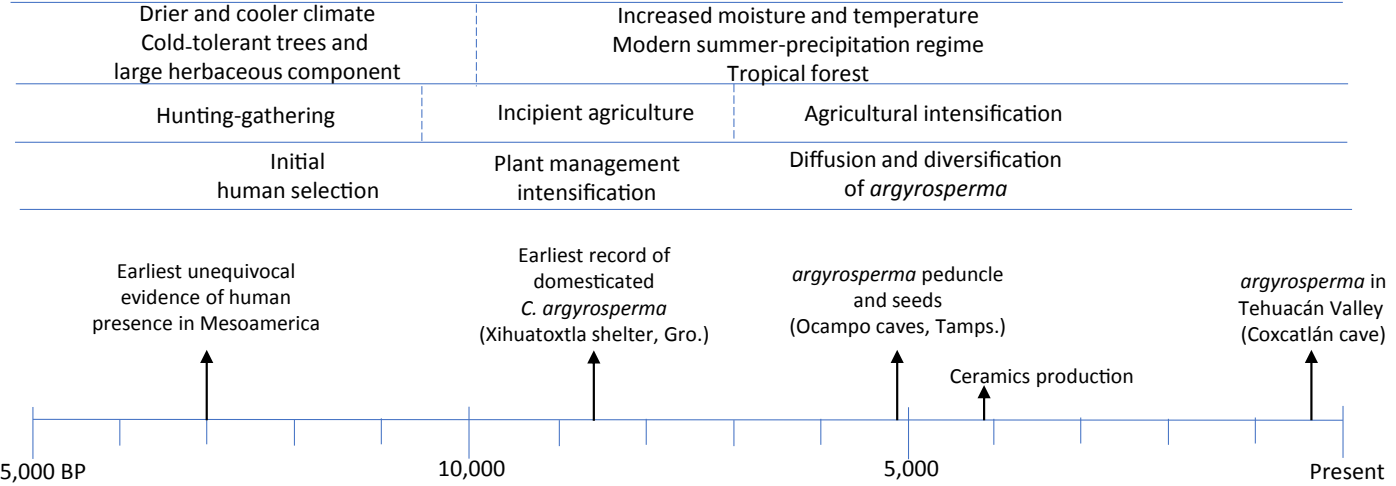

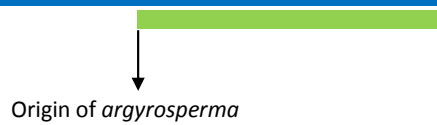

Hypothetical origin of Eastern

in the lowland of Jalisco

populations based

migration events

Figure 6. Model of Cucurbita argyrosperma domestication based on archaeological and genetic data (Smith 1997; Sanjur et al., 2002; Ranere et al., 2009; Zizumbo-Villarreal and Colunga-GarcíaMarín, 2010; Stinnesbeck et al., 2017). The colored lines represent the presence of each $C$. argyrosperma population in Mesoamerica (blue = sororia populations, green $=$ argyrosperma populations in Western Mexico, red = argyrosperma populations in Eastern Mexico). 